PAPER

\title{
Sovereignty, individuality, and sustainability
}

\author{
John Cairns, Jr.* \\ Department of Biology, Virginia Polytechnic Institute and State University, Blacksburg, Virginia 24061, USA
}

\begin{abstract}
Humans must acknowledge that the biosphere is the essential support for all living organisms. In order to achieve sustainable use of the planet, humans must proceed beyond egocentrism, ethnocentrism, homocentrism, and biocentrism to ecocentrism. National states, with present policies, are a major obstacle to sustainable use of the planet. However, there is some evidence that the individual has increasing sovereignty at the expense of both nation states and the environment. Still, the primary obstacle to sustainability is inherent in the present system of sovereign nation states. The basic question is how much sovereignty must nation-states and individuals relinquish to preserve the health of Earth's biospheric life support system. A free and open exchange of thoughts on this subject is long overdue. To achieve sustainable use of the planet, humankind must view its identity within the context of the interdependent web of life.
\end{abstract}

KEY WORDS: Sustainability $\cdot$ Sovereignty $\cdot$ Individuality $\cdot$ Eco-ethics $\cdot$ Natural systems Resale or republication not permitted without written consent of the publisher

The universe rewards us for understanding it and punishes us for not understanding it. When we understand the universe, our plans work and we feel good. Conversely: if we try to fly by jumping off a cliff and flapping our arms the universe will kill us.

Cohen \& Stewart, 1994

We like to believe that if we secure adequate data bearing on a scientific problem, then anybody with normal intelligence who takes the trouble to become acquainted with these data will necessarily arrive at the same conclusion regarding the problem in question. We like to speak of conclusions demonstrated, settled, proved and established. It appears, however, that no evidence is powerful enough to force acceptance of a conclusion that is emotionally distasteful.

Dobzhansky, 1945

\section{INTRODUCTION}

Earth's carrying capacity for humans may well be exceeded in the 21st century due to both population growth and rapidly increasing use of resources. Sovereignty of both individuals and nation states is destructive of the interdependent web of life of which humans are a part. Sustainable use of the planet will probably require rethinking the autonomy of both individuals and nation states, as well as the acknowledgment of interdependence. Humankind can survive only if a new concept called eco-ethics is generally accepted (Kinne 2002).

The planet contains a large number of nation states, each with its own idiosyncratic history, stage of techno- logical development, biogeochemical identity, and relationship with natural systems. All must orchestrate sustainable use of the planet in ways that are congruent with the rest of the world. Efforts to assist or coerce laggard nation states are likely to have a perverse effect and provoke resentment instead of gratitude. There are many reasons why a major global crisis may result in continuation of unsustainable practices as powerful nation states attempt to maintain the status quo. Any nation state that believes itself capable of 'going it alone' is likely to resist any major global undertaking such as sustainable use of the planet. Most nation states persist in a secular view of the world because joining a global community effort is perceived as a loss of identity and national prerogatives. This exacerbates the problem 
because there is a tendency to focus on 'urgent' (from its perspective) short-term problems and ignore long-term problems (from a global perspective). This euphoric arrogance ignores the fact that the planet is too complex and multidimensional to focus on one issue as if it were independent from other issues. In sustainable use of the planet, interconnectedness must be central to all decisions and the implementation of these decisions. The present world is one in which advanced technology is being used in an ethical framework that is, at best, two or three centuries behind the technology. This is a very dangerous paradox in an era when economic and technological growth are worshipped and ethics or ethos rarely mentioned. The Random House Dictionary, 2nd edition, defines sovereign as 'a person who has sovereign power or authority or a monarch; a king, queen or other supreme ruler.'

Clearly, most people associate sovereignty with nation states and rarely with individuals, although the latter have acquired more independence in recent years. It is difficult to visualize increased individual sovereignty in an era of resource scarcity since humans are dependent upon Earth's ecological life support system, and, on an increasingly urbanized planet, most people are dependent on outside sources of food, energy, and materials.

Davidson \& Rees-Mogg (1997) describe a new revolution of power, which they feel is liberating individuals at the expense of nation states. They make a case for this fourth stage of human society, preceded by three earlier stages of economic life: (1) hunting-gathering societies, (2) agricultural societies, and (3) industrial societies. Despite negative reviews by some prominent newspapers (e.g. The Wall Street Journal) and other news media of this and other publications, I found this book well researched and well reasoned. However, their vision was difficult to reconcile with sustainable use of the planet. Humans evolved as a small group species, and the analysis of Davidson \& Rees-Mogg (1997) is compatible with this viewpoint, but not with the gigantic groups that exist today.

Sustainable use of the planet is based on the assumptions that:

- a harmonious, mutualistic relationship can be developed between human society and natural systems

— individuals will not abuse the commons (i.e. natural capital) but use it equitably and fairly, including sharing of resources with other species in the planet's ecological life support system

- sustainable resource allocation and partitioning will continue indefinitely and, thus, leave a habitable planet for future generations

- the taboo common to most social orders, which forbids thinking about how they will end and the degree to which present practices will affect the end, will be banished
- society will abandon an outmoded cultural paradigm rather than retain a facade that gives the illusion of continuity

- natural capital will be preserved and accumulated even at the cost of human privation during 'hard' times because it constitutes the ecological life support system essential to the well being and survival of human society

- some group or organization must transcend what economists term 'public goods dilemmas' (e.g. Ledyard 1994) to protect natural capital in the commons and on private property, including restraining and punishing individuals who impair the ecological life support system

— violence (i.e. terrorism, war, ethnic and religious conflict, etc.) must be kept to a minimal level. The advent of biological weapons of mass destruction has made violence prevention extremely difficult, arguably impossible. Durant \& Durant (1968, p. 81) noted that, in the last 3,421 years of recorded history, only 268 have seen no war. Of course, war is not the only manifestation of violence

- human society must more closely resemble natural systems in which the most productive individuals do not subsidize the less productive, especially if the latter have an exponential rate of population increase and the former (productive) do not.

\section{THE TYRANNY OF CUMULATIVE, SMALL DECISIONS}

Individuals make a series of small, seemingly insignificant decisions daily. However, the cumulative impact of these decisions can destabilize both human society and the planet's ecological life support system and affect happenings from global warming to congested traffic. In the context of this discussion, the important outcome is the reduction or loss of sovereign power by both individuals and nation states. The resulting tyranny is clearly beyond the control of individuals unless they act in concert and probably beyond effective control by nation states because they lack the power to police such a multitude of individually small decisions. The concept of carrying capacity is a perfect example of cumulative impact at a global level. The basic issue is the carrying capacity of the planet for Homo sapiens. However, each nation state must stay within its carrying capacity, as must each of the political and ecological subdivisions within it. At present, there is a misapprehension that the problem is only global, and the subunits have no major role. This erroneous assumption is one of the major obstacles to achieving sustainable use of the planet. 


\section{CARRYING CAPACITY — A COMMUNAL EFFORT}

Immigration, both legal and illegal, affects carrying capacity. Kavanaugh (2002) notes that illegal immigrants number at least 7 million, possibly 8 million, and are growing by 500,000 per year according to the US 2000 Census. More than 7 million tourists, business visitors, foreign students, and temporary workers arrived in 2001 as non-immigrants. However, the US Immigration and Naturalization Service acknowledges that it lacks a reliable tracking system to determine how many of these visitors left the country after their visas had expired. Under these circumstances, i.e. the US cannot reliably determine how many people are in the country or control the number of illegal immigrants or how this number will increase in the future, determinations of carrying capacity are exceedingly difficult, arguably impossible. Furthermore, in an exponentially growing population, the indigenous peoples can exceed the carrying capacity in a century or less. Reference is made to indigenous peoples to emphasize that carrying capacity is both a global and local problem. The global problem cannot be resolved unless the geographic, political, and ecological subunits solve the carrying capacity problem. Immigration into the US is a major factor in global carrying capacity for two reasons - (1) if present rates are continued and the immigration birth rate is higher than that of the general population, the US will be quickly pushed beyond its carrying capacity, and (2) the US and Canada have the largest ecological footprints on the planet, that is, per capita use of resources is very high; if immigrants reach a comparable level of use, there will be a much greater effect on the planet's carrying capacity than now exists. Thus, a large number of seemingly insignificant decisions to migrate or have a large family can adversely affect carrying capacity and endanger, even tyrannize, an entire population.

A number of countries have a birth rate below replacement rate (e.g. Russia, Italy), but world population continues to increase by approximately 80 million per year. On a finite planet with a finite carrying capacity, this growth is not conducive to sustainability. The most populous nation, China, is approaching population stabilization by means of peer pressure and sanctions.

\section{THE MYTH OF RUGGED INDIVIDUALISM}

The term 'rugged individualism' is used to illustrate the myth that individuals are self-sufficient and not dependent upon the planet's ecological and technological life support systems. This myth is very dangerous since it fails to recognize the marked interdependence at all levels of organization from individual to community to state or province to nation state to planet.

Cultural dogmas impede the quest for sustainable use of the planet, for example, the belief that humans have conquered nature. The tremendous technology developed in the last century has deliberately or inadvertently destroyed or degraded ecosystems worldwide. On the other hand, numerous species (called pests) defy attempts to eliminate them or control them, and other species have been domesticated to serve humans. Culture has placed humankind on a higher plane than the brutish 'lower' organisms. However, as Ehrlich (2000) has noted, the evolutionary processes that created humans also created an astonishing array of other organisms that both surround humans and support them. More important, these other life forms were responsible for generating the most important features of the environments that in turn have shaped the evolution of humankind. During the quest for sustainability, humankind will shape nature and it, in turn, will shape human culture. As Kahneman (1980) remarks, 'The increase in man's power over his environment has not been accompanied by a concomitant improvement in his ability to make rational use of that power.' Thus, errors in judgment during the quest for sustainability will shape human culture as well as sound judgment.

\section{THE COMPOSITION OF ETHICAL SYSTEMS}

Usually, ethical systems are focused on the values of one species - Homo sapiens. Generally, ethical concerns are extended beyond the human species if other life forms are perceived as valuable to humans. Species other than human are perceived as valuable because they collectively constitute the planet's ecological life support system. As ecological literacy increases, sentient organisms are recognized as valuable in and for themselves. The next step is to go beyond organisms, and affection and concern may be extended to special places and/or systems such as landscapes, old growth forests, coral reefs, or prairies. The major weakness of ethics at present is that humans get the most attention while the ecological life support system gets the least. Fortunately, publications have been formulated that will facilitate this transition. Daily \& Ellison (2002) provide a superb documentation of the utility of nature. Wilson (2002) espouses quick and decisive action to save Earth's biological heritage and explores the ethical and religious basis for doing so. Orr (1992) analyzes what governments, corporations, utilities, international agencies, and individuals can do to facilitate the transition to sustainable use of the planet. Particular attention is given to what schools, colleges, and universities can do to assist in 
the transition from unsustainability to sustainability. In short, what should people know and how should they learn it? Odum (1997) discusses how the field of ecology has matured enough to be viewed as the basic science of the total environment. Since ecology is an integrative science, it can serve as a communication 'bridge' between science and society.

Three books have influenced my thoughts about the quest for sustainable use of the planet. Torrance (1998) has produced a superb compendium of ways in which humankind has understood and represented the natural world. The unifying theme is the ethic resulting from the possible relationships with nature. Hauser (2000) provides some excellent insights that should markedly reduce anthropomorphosis. It illustrates how animals are adapted to their ecological niches and provides information that should increase the empathy of humans for other life forms. Brown (2001) depicts an environmental revolution that could follow the industrial revolution and that is driven by humankind's instinct for survival. Central to his model is discarding the paradigm that views the environment as a subset of the economy and replacing it with the view that the economy is a subset of the environment.

\section{WE ARE DEFINED BY THE QUESTIONS WE ASK}

Both individuals and societies are defined by the questions they ask, the questions they avoid, and how they respond to stochastic events. Among the questions are 'Can an individual or species be sovereign?' and 'What should the role of humankind be in the interdependent web of life and how dependent are humans upon it?'

Plato said 'The life which is unexamined is not worth living.' Psychologist PC McGraw (2001) wrote 'You need to know your highest best use in this world, and then to pursue it.' He further states 'You cannot change what you do not acknowledge.' The Random House Dictionary states that 'to define' is 'to explain or identify the nature or essential qualities of'. The questions we ask define us, not nation states or rugged individuals. Illustrative, defining questions about sustainable use of the planet are: (1) How can I learn to live sustainably? (2) Which of my present practices are unsustainable?

Is an individual ever sovereign? The US is regarded as the world's only superpower, yet it cannot control either the illicit flow of large amounts of drugs or immigrants into its country. This situation fits the hypothesis of Davidson \& Rees-Mogg (1997) in which individuals are liberated at the expense of the nation state. However, even the most liberated individuals are still vulnerable to stochastic events such as earth- quakes and global climate change. Wealth is often associated with power, but even the wealthiest individuals are dependent on other individuals for food and protection and on the planet's ecological life support system for a favorable maintenance of atmospheric gas balance and other ecosystem services.

\section{Illustrative unasked questions}

The questions that follow are rarely asked by nation states, rugged individuals, businesses, or most of human society. Failure to ask appropriate questions will ensure the continuation of unsustainable practices. The questions are a response to the failure to live sustainably. It is important to recognize that the time frame for these questions is whatever length of time humans expect to live on habitable planet.

- How will finite Earth's carrying capacity be determined? Two obvious means of doing so are: (a) exceeding the carrying capacity and increasing human misery and (b) estimating the carrying capacity using quality of life indices.

- How will the conditions necessary for sustainable use of the planet be enforced? Since sustainability is both a local and a global issue, enforcement will be a major problem unless individuals accept a major responsibility for implementing the quest for sustainability.

- How will individual 'rights' be affected by the quest for sustainable use of the planet?

- If the planet's carrying capacity for humans is exceeded, what organization will be responsible for the return to sustainable use?

- How much of the planet should be set aside for natural ecosystems?

- How will the health of the biospheric life support system be monitored?

- How will planetary biodiversity be maintained?

- If the human population size and level of affluence keeps changing, how will the resources needed by humankind's descendants be estimated? If both population size and level of affluence (i.e. use of resources) continue to increase and the disparity between the wealthiest and poorest individuals continues to widen, what remedial measures should be taken? Durant \& Durant (1968, p. 57) conclude that the concentration of wealth is both natural and inevitable and is periodically alleviated by violent or peaceable partial redistribution. The distribution of resources questions may be one of the major obstacles to sustainable use of the planet.

- What organization will be responsible for confirming that the conditions for sustainability are being met? Individuals respond best to meeting conditions that will favor themselves, their family, and their state or 
nation. The further the issue is removed in either time or cultural ties (i.e. family and friends), the less attention it gets. A strong dedication to eco-ethics is essential since sustainable use of the planet is supposed to continue for an indefinite period of time, benefit future generations, and preserve natural capital (including millions of species other than humans) and the condition of Earth's ecological life support system. An important subsidiary question concerns how this organization will be supported.

- How will disputes about the conditions of sustainability be met? Science and technology are important factors in achieving sustainable use of the planet, but ethical and moral values are also important in determining both the planetary and human condition. In addition, the system must respond quickly to any and all changes in the conditions needed for sustainability. - How will the social capital ${ }^{1}$ essential to sustainable use of the planet be preserved and increased? The extreme, sovereign individual may view the self as independent of or in control of human society. In a less extreme form, the sovereign individual may feel no need to foster and accumulate social capital.

\section{Illustrative asked questions}

Understandably, most of the asked questions have short time horizons, often only hours or days: What should I wear today? What should I have for lunch and dinner? For those in the US, will Social Security be financially sound when I retire? Some of these questions are important in the temporal scale for which they are made - e.g. should I pass the vehicle ahead of me on a curve in the road where the visibility is poor? Should I get nursing home care insurance for my old age? What should I do to make life better for my descendants?

Short-term or small-distance questions are usually egocentric or homocentric. Long-term or largedistance questions are most commonly either homocentric or ecocentric. Almost all of these questions are, of course, a mixture of egocentric, homocentric, and ecocentric. The important question is how to balance these three views of life. Humankind has never faced a problem on this temporal and spatial scale. Since the evidence base for achieving sustainable use of the planet is small and since we must achieve sustainabil-

\footnotetext{
${ }^{1}$ Social capital is the aggregate of the positive interactions between individuals and cultures. The 1995 Wealth Index of the World Bank (see pp. 57-66 on the internet site of the 1995 edition or the more recent 1997 report) estimated that the sum value of human capital (social and cultural systems) is three times larger than all the financial and manufactured capital reflected on the global balance sheet
}

ity to be confident what methods and procedures are essential, the effort must be flexible. However, it would be a mistake to change practices too suddenly because there is often a considerable lag time before ecosystems adjust to new conditions. Human society also takes time to adjust to new conditions. As a consequence, it seems advisable to be patient when a response seems to be favorable so that much validating evidence can be accumulated. On the other hand, the response should be rapid when deleterious effects upon ecosystems are evident. Both false negatives and false positives are virtually certain to occur, especially in the early stages of the quest for sustainable use of the planet. False negatives occur when the monitoring system fails to detect deleterious effects and false positives signal deleterious effects when there are none.

\section{SUBSIDIES}

Subsidies are primarily given by nation states to special interest groups that have argued for them persuasively. The funds usually come from taxes and other similar revenues. Subsidies also come from such organizations as the World Bank and also from individuals. One of the prime goals of subsidies is economic growth, but this does not ensure that the resulting practices are sustainable. For example, one nation state may hope to gain an economic advantage over one or more other nation states. However, this competition may result in loss of natural capital (bad for sustainability) rather than the accumulation of natural capital (good for sustainability). It is essential to recognize that government subsidies to special interest groups probably will not result in improvement of the human condition.

A major obstacle to achieving a balance is the powerful special interest groups that are often subsidized with tax dollars (Myers \& Kent 2001). Some subsidies (i.e. education) benefit the entire society while others benefit special interest groups and may simultaneously have adverse environmental effects (e.g. Roodman 1996, Drew 1999). Subsidizing special interest groups that damage the environment is neither eco-ethical nor a sound business practice. Furthermore, using tax monies for subsidies diminishes the sovereignty of the individual citizen by collecting funds in the form of taxes that subsidize a select group and may harm the individual (e.g. pollutants, etc.).

\section{REQUIEM FOR SOVEREIGNTY}

The Davidson \& Rees-Mogg (1997) discussion of the loss of power of the 20th century nation state to the individual has already been described. This essay 
speculates that individual sovereignty is an illusion. However, Scott (1982, p. 33) notes that, for global systems to work reasonably well, a large number of subsystems must consistently function effectively.

Failure or inappropriate functioning of any one of these will cause problems. Risk is inherent in the system and would exist even if all individuals attempted to cooperate. Scott (1982, p. 203) further remarks that, since the international or global system now creates problems faster than solutions, increased cooperation and coordination are essential. Orr (1992, p. 45) notes that the ultimate expression of sovereignty - war has become too destructive for both victor and vanquished. Over a decade after Orr's book was published, human society has ample evidence of terrorism and other displays of individual power. Also, weapons of mass destruction, including biological warfare, have further strengthened Scott's view on nation state power and the likelihood of lose/lose results.

\section{INTERDEPENDENCE}

Clearly, sustainable use of the planet requires both a recognition of interdependence of all individuals within the human species and an acknowledgment that it is dependent upon the interdependent web of life. Ehrlich (2000) believes that biological evolution is not sufficiently rapid to make the necessary changes. However, he feels that cultural evolution might do so, despite the evidence that it has led many past civilizations to extinction. He further states that humans are essentially small-group animals attempting to live, with increasingly rare exceptions, in gigantic groups — trying to maintain health, happiness, and a feeling of connectedness in an increasingly impersonal world in which individual natures are based on even smaller fractions of society's culture. One might easily conclude, if these assumptions are accepted, that sovereignty is outmoded at all levels of organization individual, nation state, bioregional, and global.

Even if all these adjustments are made, there is no guarantee that Homo sapiens can exist indefinitely on this planet. What is highly probable is that failure to attempt these transitions will shorten the time humankind can persist on the planet.

\section{CONCLUSIONS}

Individuals may believe they are sovereign (supreme ruler of Earth), but no organisms exist as separate entities. All are part of Earth's geoecosystem, without which nothing could exist. Common sense and research in ecology provide persuasive evidence that organisms, even humans, are not self-sufficient. Given the dependence of humankind on the biospheric life support system, the concept of individuals as sovereign is not only counterproductive but may even be fatal. Sustainable use of the planet requires humility and a greater sensitivity for the health of the planet's biosphere.

This article covers only one aspect of the quest for sustainable use of the planet - sovereignty. It is clear that sustainability requires replacement of all unsustainable practices, especially those that damage the integrity of the planet's ecological life support system. One hopes that the ethical imperatives congruent with this goal will be discussed at length in ESEP by individuals from all parts of the planet. Focusing on ecologically destructive practices is the responsibility of all humankind. One alternative is to practice sustainability at the individual level by an informed, ecologically literate global community. If this appears hopeless, a less satisfactory alternative is a transnational organization (e.g. such as the UN) to provide sustainability polices and enforce global compliance. The latter alternative will be unattractive to many individuals, but the alternative of continuing to live unsustainably will leave a less habitable, even uninhabitable, planet for posterity. The quest for sustainable use of the planet is a complex, multivariate goal. Each individual can become literate about sustainability, think about and act on this information - live up to the species descriptor Homo sapiens, and communicate thoughts and ideas to EEIU and ESEP. Alternatively, one can deny reality, take an anti-depression medication, and live for the moment. This is clearly unethical behavior.

Acknowledgments. I am indebted to K Cairns for transferring the handwritten manuscript to the word processor and to my editorial assistant D Donald for processing this manuscript for publication. WT Hendricks called the book The Sovereign Individual to my attention.

\section{LITERATURE CITED}

Brown LR (2001) Eco-economy. WW Norton, New York, NY Cohen J, Stewart I (1994) The collapse of chaos. Viking Press, New York, NY

Daily GD, Ellison K (2002) The new economy of nature. Island Press, Washington, DC

Davidson JD, Rees-Mogg W (1997) The sovereign individual: how to survive and thrive during the collapse of the welfare state. Simon and Schuster, New York, NY

Dobzhansky T (1945) Review of 'Evolution, creation, and science' by Frank Lewis Marsh. Am Nat 79:73-75

Drew E (1999) The corruption of American politics: what went wrong and why. Birch Lane Press, Secaucus, NJ 
Durant W, Durant A (1968) The lessons of history. MJF Books, New York, NY

Ehrlich PR (2000) Human natures. Island Press, Washington, DC Hauser MD (2000) Wild minds. Henry Holt and Company, New York, NY

Kahneman D (1980) Human engineering of decisions. In: Kranzberg M (ed) Ethics in an age of pervasive technology. Westview Press, Boulder, CO, p 190-192

Kavanaugh F (2002) Communication on the dimensions of the problem facing the Immigration and Naturalization Service and law-enforcement agencies in monitoring and controlling foreign visitors, especially those in the USA under student visas. Biocentric Institute, Washington, DC

Kinne O (2002) EEIU Brochure. English Original. InterResearch, Oldendorf/Luhe, Germany

Ledyard J (1994) Handbook of experimental economics. Princeton University Press, Princeton, NJ

Editorial responsibility: Mary Batson (Managing Editor), Oldendorf/Luhe, Germany
McGraw PC (2001) Self matters: creating your life from the inside out. Simon and Schuster, New York, NY

Myers N, Kent J (2001) Perverse subsidies. Island Press, Washington, DC

Odum EP (1997) Ecology: a bridge between science and society. Sinauer Associates, Sunderland, MA

Orr DW (1992) Ecological literacy: education and the transition to a postmodern world. State University of New York, Albany, NY

Roodman DM (1996) Paying the piper: subsidies, politics, and the environment. WorldWatch Institute, Washington, DC

Scott AM (1982) The dynamics of interdependence. University of Carolina Press, Chapel Hill, NC

Torrance RM (1998) Encompassing nature. Counterpoint, Washington, DC

Wilson EO (2002) The future of life. Alfred A. Knopf, New York, NY

Submitted: May 9, 2003; Accepted: August 7, 2003

Proofs received from author(s): September 11, 2003

Published on the web: September 16, 2003 